\title{
An Empirical Analysis of Patterns in the Japanese Long-Term Care Insurance System
}

\author{
Olivia S. Mitchell ${ }^{\mathrm{a}}$, John Piggott ${ }^{\mathrm{b}}$ and Satoshi Shimizutani ${ }^{\mathrm{c}}$ \\ ${ }^{a}$ Department of Insurance \& Risk Management, Wharton School, University of Pennsylvania, 3641 Locust \\ Walk, 304 CPC, Philadelphia, PA 19104-6218, U.S.A. \\ E-mail: mitchelo@wharton.upenn.edu \\ ${ }^{\mathrm{b}}$ School of Economics, University of New South Wales, Sydney 2052, Australia. \\ E-mail: J.Piggott@unsw.edu.au \\ ${ }^{\mathrm{c}}$ Institute for International Policy Studies (IIPS), Toranomon 30 Mori Building, 6F Toranomon 3-2-2, \\ Minato-ku, Tokyo 105-0001, Japan. \\ E-mail: sshimizutani@iips.org
}

The recently enacted Japanese long-term care (LTC) system was implemented to reduce the so-called "social hospitalization" or warehousing of the elderly in expensive medical facilities. This paper seeks to evaluate recent patterns in Japanese LTC use and examine the factors associated with LTC utilization patterns. We show that the use of LTC in Japan particularly home care - is growing rapidly, as the elderly consumers find subsidized LTC care preferable to and more available than hospitalization. At the same time, regional disparities in terms of entitlement and care use persist and are likely to grow.

The Geneva Papers (2008) 33, 694-709. doi:10.1057/gpp.2008.25

Keywords: nursing home; long-term care insurance; home health care; ageing risk; elder care; means-testing

\section{Introduction}

Japan is one of the fastest ageing nations on earth: about one-fifth of the population is currently aged $65+$, roughly twice the U.S. ratio, and this will more than double by 2050. Not surprisingly, the Japanese healthcare system has come under increasing stress as a result of rising numbers of long-lived older persons demanding higher medical care and increases in the rate of long-term care (LTC) usage. Healthcare costs of persons $65+$ averaged five times those of younger persons in Japan in 2000, and the fraction of the elderly needing nursing home care is projected to rise dramatically over the next two decades. ${ }^{1}$ Some 90 per cent of the growth in healthcare costs in recent years has been attributed to population ageing. ${ }^{2}$ As a result, Japanese policymakers are deeply concerned about forecasts of high levels of hospitalization and expensive medical care for older persons in the years to come. At the same time, regional discrepancy has expanded, which has put pressure on the current LTC insurance scheme whose framework is centralized. ${ }^{3}$

\footnotetext{
${ }^{1}$ Ikegami and Yamada (1996).

${ }^{2}$ Yashiro et al. (2006).

${ }^{3}$ Mitchell et al. (2006).
} 
In response to these forecasts, the national health authority has over the last several years instituted a number of changes in the Japanese LTC delivery model. This paper first briefly describes the Japanese LTC system, drawing on existing studies and providing updates on recent policy developments. Next we use prefectural-level data to study the empirical factors associated with entitlement and utilization to disentangle some of the recent utilization trends. An interesting feature of the Japanese approach to LTC is that, while the framework and price and benefit parameters are centralized, it relies heavily on local or decentralized decision-making regarding service use. We present our estimates and offer an interpretation of findings. Last we discuss possible policy implications.

\section{A brief overview of Japan's old-age care system ${ }^{4}$}

The Japanese healthcare system relies on mandated universal medical coverage tied to participants' jobs or regions of residence. For employees, municipalities and firms must offer mandatory healthcare coverage financed by premiums levied on household heads (in the case of the community-based plans), or shared half by employers and half by employees (for company-based plans). The self-employed pay half the premium and the remaining half is compensated by tax revenue. The special position of retired persons ${ }^{5}$ is summarized by Mitchell et al. ${ }^{6}$ and others. ${ }^{7}$ In the main, medical services for the older population are provided via a national mandatory plan known as the National Health Insurance programme that provides hospitalization and medical services to the elderly. ${ }^{8}$

The Japanese healthcare system has experienced several reforms over the years, and a timeline of key policy changes appears in Table 1. Many authorities have praised Japan's relatively low healthcare expenditures, compared to international developed nation standards, said to result from strict government control over medical services and pharmaceuticals, fixed reimbursement for hospital services, and a low "intensity" level of care per patient. ${ }^{9}$ At the same time, under the free hospitalization programme beginning in 1973, the number of "social hospitalized" elderly who did not need intensive medical care expanded rapidly. The government's "Gold Plan," initiated in 1990 and revised in 1994, responded to this by seeking to increase the number of nursing home beds, adult daycare and home health aid providers. ${ }^{10}$

In addition, Japanese over the age of 40 are included in a national LTC insurance (LTCI) programme recently mandated by the national government. Before the introduction of the public system, LTC services were provided through the "distribution

\footnotetext{
${ }^{4}$ This section draws on and extends Mitchell et al. (2006).

${ }^{5}$ As noted in ibid., Japanese firms are being required to gradually move up the mandatory retirement age to 65 by FY2014.

${ }^{6}$ Ibid.

${ }^{7}$ cf. Ikegami and Campbell (1999).

${ }^{8}$ Those services for people aged $75+$ are provided through an independent insurance scheme from April 2008.

${ }^{9}$ Yashiro et al. (2006).

${ }^{10}$ Mitchell et al. (2006).
} 
Table 1 Historical developments in Japan's healthcare system

\begin{tabular}{|c|c|}
\hline Year & Policy or programme development \\
\hline 1961 & Universal coverage of medical services established \\
\hline 1973 & Free medical care services provided to those aged 70 and over \\
\hline 1981 & $\begin{array}{l}\text { Contribution to the cost sharing of medical expenses increased; } \\
\text { Policy of fee exemption for high-cost medical services introduced }\end{array}$ \\
\hline 1983 & $\begin{array}{l}\text { Free medical services for those aged } 70 \text { and over abolished, and elderly patients required to } \\
\text { make monthly contributions of } 400 \text { yen (equivalent to US\$2 based on the } 1983 \text { exchange } \\
\text { rate) per month for outpatient care and } 300 \text { yen per day for inpatient care; } \\
\text { Law on Health Service System for the Elderly (those aged } 70 \text { and over) established }\end{array}$ \\
\hline 1984 & 10 per cent co-insurance for non-elderly introduced \\
\hline 1986 & $\begin{array}{l}\text { Elderly contributions increased: } \\
\text { For outpatients, from } 400 \text { to } 800 \text { yen per month } \\
\text { For inpatients, from } 300 \text { to } 400 \text { yen per day }\end{array}$ \\
\hline 1987 & Law on the Health Services Facilities of the Elderly enforced \\
\hline 1990 & 10-year Gold Plan implemented \\
\hline 1993 & $\begin{array}{l}\text { Elderly contributions increased: } \\
\text { For outpatients, from } 900 \text { to } 1,000 \text { yen per month } \\
\text { For inpatients, from } 600 \text { to } 700 \text { yen per day }\end{array}$ \\
\hline 1995 & Elderly outpatients' contributions increased from 1,000 yen to 1,010 yen per month \\
\hline 1996 & $\begin{array}{l}\text { Elderly contributions increased: } \\
\text { For outpatients, from } 1,010 \text { to } 1,020 \text { yen per month } \\
\text { For inpatients, from } 700 \text { to } 710 \text { yen per day }\end{array}$ \\
\hline 1997 & $\begin{array}{l}\text { Co-insurance for non-elderly raised from } 10 \text { to } 20 \text { per cent } \\
\text { Elderly contributions increased: } \\
\text { For outpatients, from } 1,020 \text { yen per month to } 500 \text { yen per visit } \\
\text { For inpatients, from } 710 \text { to } 1,000 \text { yen per day }\end{array}$ \\
\hline 1998 & Elderly inpatients' contributions increased to 1,100 yen per day \\
\hline 1999 & $\begin{array}{l}\text { Elderly contributions increased: } \\
\text { For outpatients, from } 500 \text { to } 530 \text { yen per visit } \\
\text { For inpatients, from } 1,100 \text { to } 1,200 \text { yen per day }\end{array}$ \\
\hline 2000 & $\begin{array}{l}\text { Long-term Care Insurance made effective; } \\
\text { Contributions for the elderly abolished and payment limits set ( } 3,000 \text { yen per month for } \\
\text { outpatients, } 37,200 \text { yen per month for inpatients) }\end{array}$ \\
\hline 2002 & $\begin{array}{l}10 \text { per cent coinsurance required of elderly patients; } 20 \text { per cent coinsurance required of } \\
\text { those with higher income }\end{array}$ \\
\hline 2003 & $\begin{array}{l}\text { Co-insurance for non-elderly increased from } 20 \text { to } 30 \text { per cent } \\
\text { Diagnosis Procedure Combination introduced at } 82 \text { specially designated hospitals }\end{array}$ \\
\hline 2006 & Co-insurance for elderly increased from 10 to 20 per cent \\
\hline
\end{tabular}

Source: Derived from Ogawa et al. (2007).

system," and the users were limited to low-income households. ${ }^{11}$ In this new scheme, the central authorities set the prices of nursing home beds, adult day-care or short-stay centres and home-care services providers. They also play important roles in setting eligibility standards and determining who is entitled for care. Specifically, older persons needing benefits under the current Japanese LTC programme can avail themselves of either in-home services (at-home care) or services at institutions

\footnotetext{
${ }^{11}$ Campbell and Ikegami (1998); Yashiro et al. (1996).
} 
(institutional care). ${ }^{12}$ Eligibility for care is set based on a local-level committee's lengthy assessment of all applicants' medical and physical status. ${ }^{13}$ This committee categorizes applicants into one of seven (as of FY 2006) levels of LTC needs, and then benefits are attached to that grouping. ${ }^{14}$ Applicants are assigned a case manager who provides a care plan; the applicant's status is then re-evaluated every 6 months. Medical care is not included in the LTC menu; rather it is delivered separately by the applicant's doctor.

Financing of the Japanese LTC system is pay-as-you-go, relying on social insurance premiums, general tax revenue and user fees. About half of the LTC system is financed by earmarked premiums from workers aged $40+$ and retirees; the remainder is split between the central government and local government entities. ${ }^{15}$ Worker and retiree premiums vary geographically, and the payments also depend on income (those with low incomes pay relatively less). Users of the LTC system also bear out-of-pocket costs via a 10 per cent co-insurance on each service used, up to a cap which can vary with income; since October 2005 they also must pay a meal charge while living in an institution, "hotel" costs which include living costs (water, electricity, and gas), and a portion of food/cooking costs. ${ }^{16}$

An interesting feature of the Japanese approach to LTC is its relatively high degree of reliance on local or decentralized decision-making regarding service use. Although the central government sets prices and types for LTC services and determines the number of units of care per pre-set level of "care need," each municipality or alliance of municipalities establishes insurance premiums, and "care managers" are assigned to determine what types of care a certified person is eligible for. In addition, there is room for each municipality to control how many people to serve with LTC via a unified certification process; local governments also must approve providers of LTC insurance (only non-profits can provide institutional care). The idea is that providers will compete locally for patients along several dimensions including quality of care, but not prices; this is more likely for non-hospital entities including home-care providers that

12 This discussion draws on Mitchell et al. (2006); JMHLW (2002, 2003); and Campbell and Ikegami (2000). An at-home care user is defined as one who uses home-visit/day services (home-visit long-term care, home-visit bathing, home-visit rehabilitation, day rehabilitation (day care), home-visit nursing care, day services, welfare devices leasing), short-stay services/short-stay care, in-home medical care management counselling, care for the elderly with dementia, elderly care provided in for-profit private homes, allowances for purchase of welfare devices, or allowances for home renovation (handrails, removal of level differences, etc.). An institutional care user is defined as one who inhabits a long-term care welfare institution for the elderly (special nursing home), long-term care health institution for the elderly, or a long-term care medical institution for the elderly. A person living in an institution other than those three types and receiving long-term care services is counted as an at-home care user. This means that the definition of institutional care is limited in Japan.

13 Ikegami (2003).

14 These groups range from the least demanding "Support Required" (the consumer can live independently but requires assistance for Instrumental Activities of Daily Livings (IADLs) to five increasingly disabled levels of "Care Required" for help in basic Activities of Daily Living (ADLs).

15 JMHLW (2002).

16 The co-payments are complicated and depend on one's income and tax status. For instance an old-age welfare pension recipient faces an out-of-pocket limit of $¥ 15,000 / \mathrm{month}$; someone exempt from municipal tax faces a limit of $¥ 24,600$ /month; and a regular taxpayer has a limit of $¥ 37,200 /$ month. 


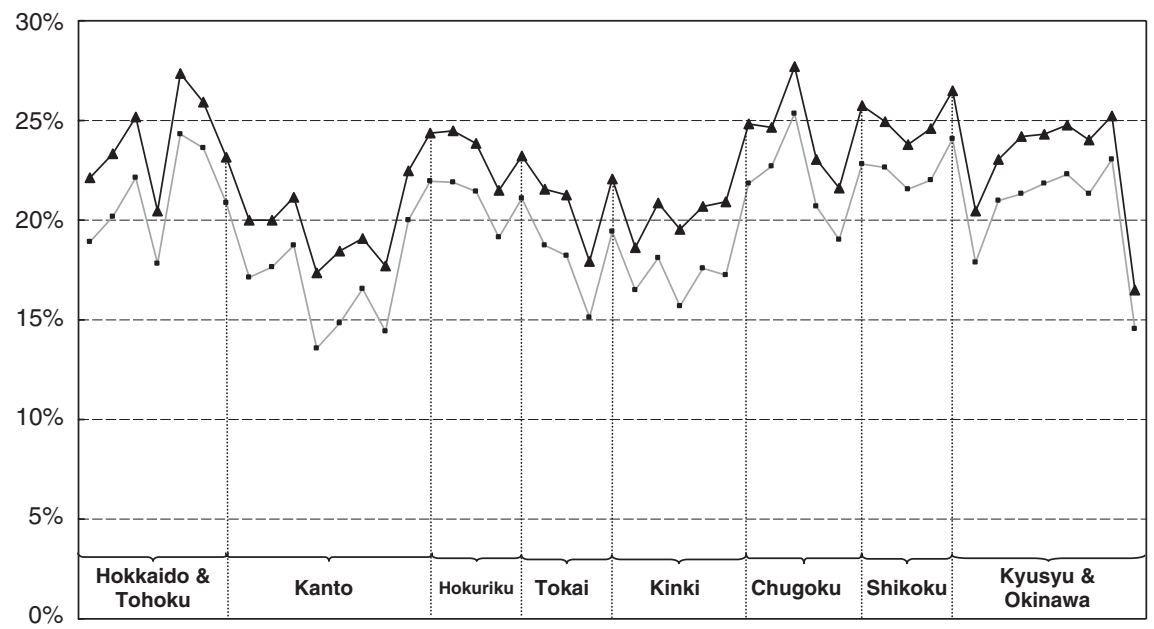

Figure 1. Population over 65 by region in Japan: 2001 (thin line) and 2006 (darker line with triangles) (population $65+/$ total population). Source: Authors' calculations using data in 2001 and 2006 provided by Statistics Bureau of Japan. The figure indicates the share of the population aged $65+$ to total population by geographic region (bottom axis). Regions indicated are as follows: the "Hokkaido \& Tohoku" region consists of seven prefectures (Hokkaido, Aomori, Iwate, Miyagi, Akita, Yamagata, and Fukushima); the "Kanto" region consists of nine prefectures (Ibaragi, Tochigi, Gumma, Saitama, Chiba, Tokyo, Kanagawa, Yamanashi, and Nagano); the "Hokuriku" region includes four prefectures (Niigata, Toyama, Ishikawa, and Fukui); the "Tokai" region includes four prefectures (Gifu, Shizuoka, Aichi, and Mie); the "Kinki" region consists of six prefectures (Shiga, Kyoto, Osaka, Hyogo, Nara, and Wakayama); the "Chugoku" region consists of five prefectures (Tottori, Shimane, Okayama, Hiroshima, and Yamaguchi); the "Shikoku" region includes four prefectures (Tokushima, Kagawa, Ehime, and Kochi); the "Kyushu \& Okinawa" region includes eight prefectures (Fukuoka, Saga, Nagasaki, Kumamoto, Oita, Miyazaki, Kagoshima, and Okinawa). See Data Appendix for details.

include for-profit and not-for-profit firms, as well as local government service organizations.

There is substantial geographic diversity across Japan in terms of where older persons are located. Figure 1 depicts the number of people aged $65+$ as a percentage of the population in 2001 and again in 2006, the most recent year for which data are available. Remarkably, in just 5 years, the older population grew 10 per cent, with some regions experiencing a rise in the fraction of people over 65 by up to 25 per cent. The difference in the figure between the highest and the lowest prefectures exceeded 10 per cent. The figure is relatively low in the Kanto and Kinki areas including large cities and in Okinawa, but it exceeds 20 per cent in most other prefectures.

Both the geographic differentials and the large changes over what is a rather short period are again apparent in Figure 2, which depicts the entitlement rate for LTC by geographic region. The entitlement rate may be defined as the number of people aged $65+$ that have been deemed to be eligible for LTC, as a percentage of the population of that age. In the earlier year, 2001, the average entitlement rate was 13 per cent, but only 5 years later this had risen by more than one-third, to 17.4 per cent; further, the figure indicates that some prefectures have more than 20 per cent of the older 


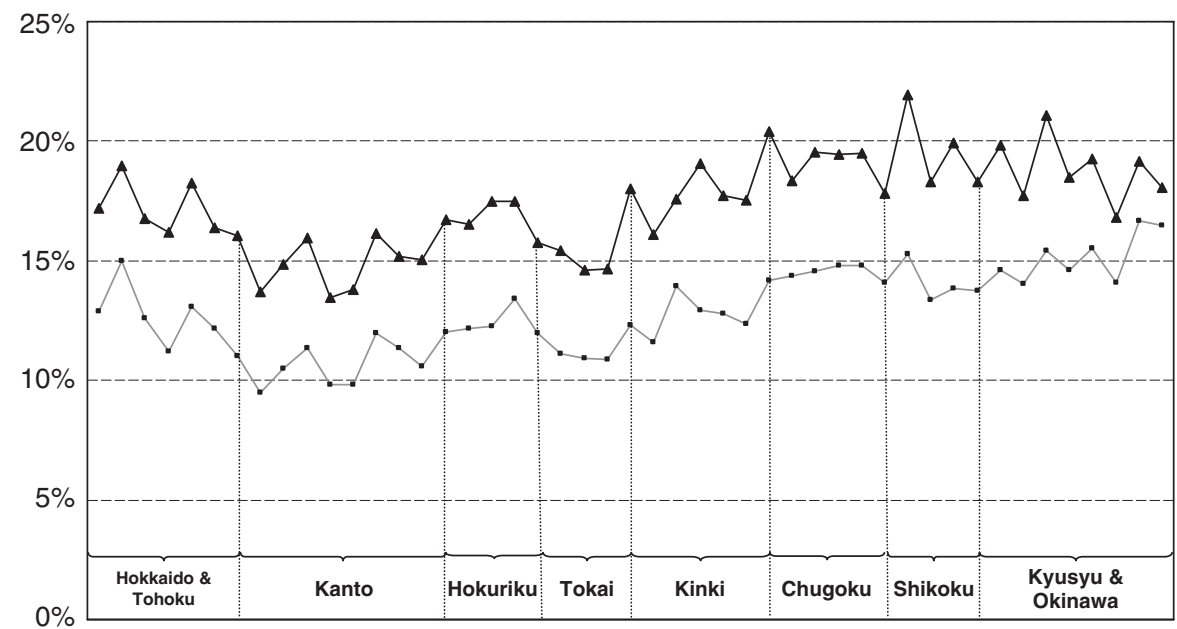

Figure 2. LTC entitlement rates by region in Japan: 2001 (thin line) and 2006 (darker line with triangles) (number entitled/population 65+). Source: Authors' calculations using data in 2001 and 2006 provided by All Japan National Health Insurance Organization and Statistics Bureau of Japan. The figure depicts the ratio of people entitled to LTC services relative to the population aged $65+$ by region. See Figure 1 and Data Appendix for details.

population entitled. At the same time, the gap between the highest and the lowest prefectures increased from 7.2 per cent in 2001 to 8.5 per cent in 2006 .

A breakdown of the overall data into utilization patterns of institutional vs. in-home care is useful, as it soon becomes clear that the summary picture conceals substantial changes in patterns of care over time. Figure 3 tracks regional patterns in the number of persons aged $65+$ using institutional care, that is, residents in the institutions, and here we see that overall, the percentage change was small in the order of 5 per cent over 5 years. We observe a large decline in the figure in Okinawa that has tight control over institutional care capacity. By contrast, the home-healthcare utilization rate grew by almost half (46 per cent). Such patterns no doubt played a key role in the reform enacted in spring 2006 under which home-care benefits from the LTCI system were reduced so as to slow the national rate of growth of costs. ${ }^{17}$ Although not indicated in the figure, the mix of capacity is changing over time: in just 5 years, the number of hospital beds per thousand persons aged $65+$ fell by 17 per cent on average, whereas the beds dedicated to LTC rose by almost 4 per cent. ${ }^{18}$ This marks a substantial change in the way care institution capacity is being allocated to the elderly in Japan.

${ }^{17}$ Ogawa et al. (2007).

18 The number of LTC beds is defined as the sum of those of long-term care welfare institutions for the elderly, long-term care health institutions for the elderly and long-term care medical institutions for the elderly. The number of non-LTC beds is defined as total number of beds in medical institutions subtracting beds for LTC. 

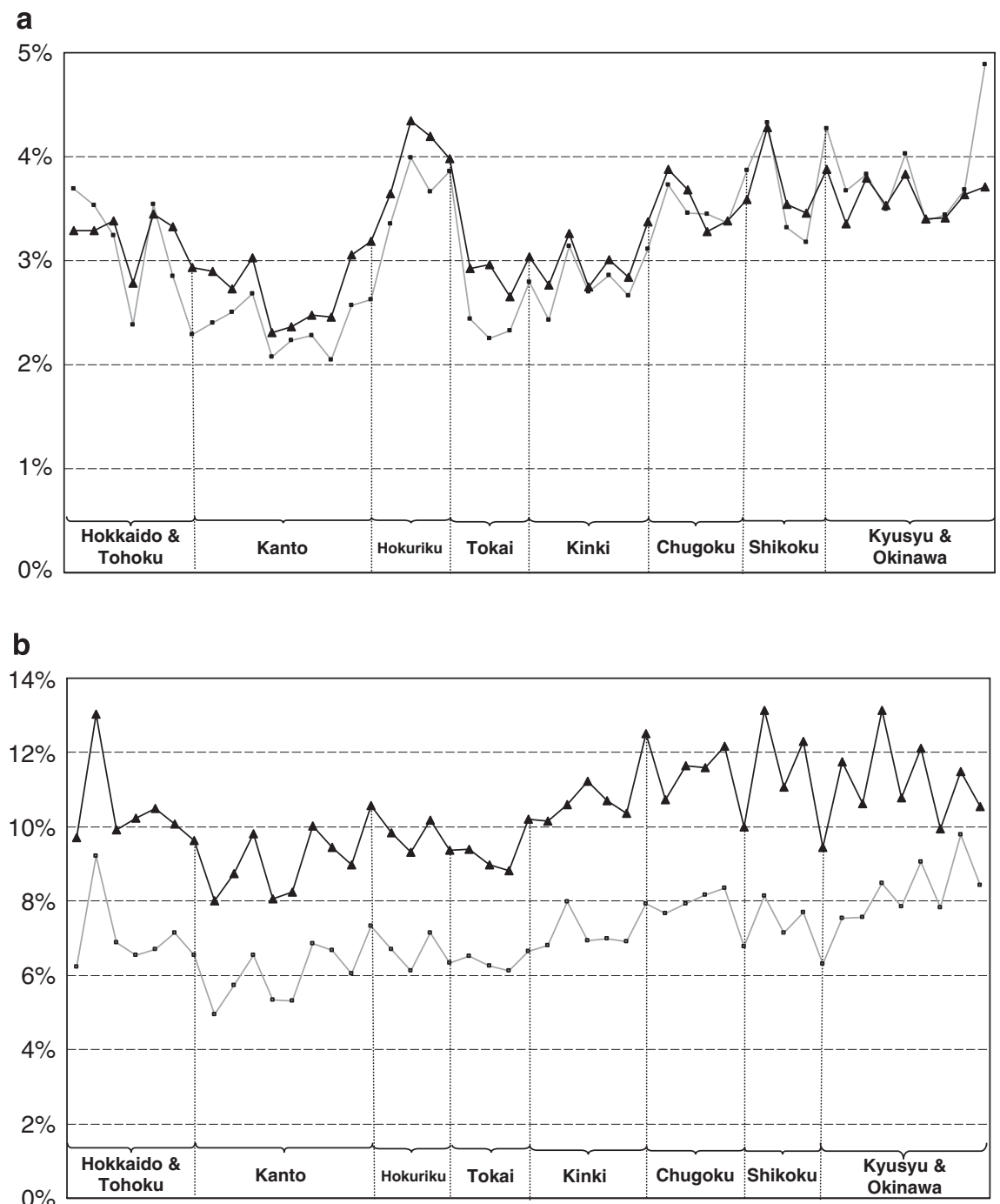

Figure 3. Utilization rates of institutional and home care by region in Japan: 2001 (thin line) and 2006 (darker line with triangles) (number using care/population 65+). (a) Institutional care utilization rates: 2001 and 2006. Source: Authors' calculations using data in 2001 and 2006 provided by All Japan National Health Insurance Organization and Statistics Bureau of Japan. The figure indicates the ratio of people using institutional care divided by the population age $65+$ by region. See Figure 1 and Data Appendix for details. (b) Home care utilization rates: 2001 and 2006. Source: Authors' calculations using data in 2001 and 2006 provided by All Japan National Health Insurance Organization and Statistics Bureau of Japan. The figure indicates the ratio of people using at-home care services to the population age $65+$ by region. See Figure 1 and Data Appendix for details. 
Table 2 Sample statistics for empirical analysis of LTC entitlement rates, institutional utilization rates and home care utilization rates for the $65+$ in Japan

\begin{tabular}{|c|c|c|c|c|c|}
\hline & Mean & Median & S.D. & Min & $\operatorname{Max}$ \\
\hline \multicolumn{6}{|l|}{ Dependent variables } \\
\hline \# Entitled/(population $65+\times 1,000)(\%)$ & 15.80 & 15.94 & 2.52 & 9.47 & 21.92 \\
\hline \# Home care users/(population $65+\times 1,000)(\%)$ & 9.23 & 9.31 & 1.71 & 4.96 & 13.23 \\
\hline \# Institutional care users/(population $65+\times 1,000)(\%)$ & 3.26 & 3.36 & 0.59 & 2.04 & 4.89 \\
\hline \multicolumn{6}{|l|}{ Independent variable } \\
\hline Population density (1,000 persons $\left./ \mathrm{km}^{2}\right)$ & 0.66 & 0.28 & 1.14 & 0.07 & 6.02 \\
\hline Population $75+/$ total population $(\%)$ & 9.66 & 9.77 & 1.95 & 5.09 & 14.79 \\
\hline Health care sector pay (million yen/year) & 4.36 & 4.40 & 0.38 & 3.38 & 5.22 \\
\hline Average household earnings (million yen/year) & 4.42 & 4.39 & 0.56 & 3.28 & 6.19 \\
\hline \# LTC beds/1,000 persons aged 65 and over & 33.62 & 34.21 & 6.03 & 20.87 & 51.07 \\
\hline \# Hospital (non-LTC) beds/1,000 persons aged 66 and over & 53.87 & 52.87 & 8.31 & 37.04 & 81.79 \\
\hline
\end{tabular}

Source: $\mathrm{N}$ observations $=282$. Data sources appear in the Data Appendix.

Note: The dependent variables refer to the share of those eligible for LTC (entitlement rate), the share entitled to home care users (home care utilization rate), and the share of institutional care users (institutional care utilization rate) of those aged $65+$ in each prefecture. The independent variables include the population per kilometer-squared (population density), the share of those age $75+$ in the population (per cent $75+$ ), annual average pay levels including bonuses for staff and assistant nurses (in 2005 real levels) (health care sector pay), annual household earnings in 2005 levels (Average HH earnings), the number of LTC beds available, and the number of non-LTC hospital beds available.

\section{Empirical specification}

In a prior study on the Japanese LTC system, we analysed 2 years of data (2001-2002) to illuminate the association between the elderly entitlement rates and utilization rates of LTC beds, on the one hand, and demographic as well as economic variables on the other. ${ }^{19}$ The present study offers a more robust analysis as it extends the data set by 4 additional years of data at the prefectural (municipality) level. Thus, the sample is now 282 (47 prefectures for 6 years) instead of the 94 observations used in our earlier work. Summary statistics on both the explanatory and dependent variables appear in Table 2 .

Our approach relates several key factors to the observed LTC entitlement rates as well as institutional-care and home-care utilization rates by the elderly. Table 3 offers three multivariable regressions for each dependent variable. Specification 1 includes as regressors the area's population density, the per cent of the population over the age of 75 , average household earnings, and healthcare sector pay. Population density proxies for urbanity; in cities, older people are hypothesized to be less likely to have offspring readily accessible to care for them. The fraction $75+$ is included to test whether LTC entitlement and utilization rates are responsive to demographic concentrations of older persons. We include healthcare sector pay to indicate whether utilization is responsive to salary levels of caregivers as input costs, and average household earnings controls on ability to pay which varies both cross-sectionally and in the time series. The household

\footnotetext{
${ }^{19}$ Mitchell et al. (2006).
} 
Table 3 Multiple regression analysis of factors associated with LTC entitlement and utilization rates

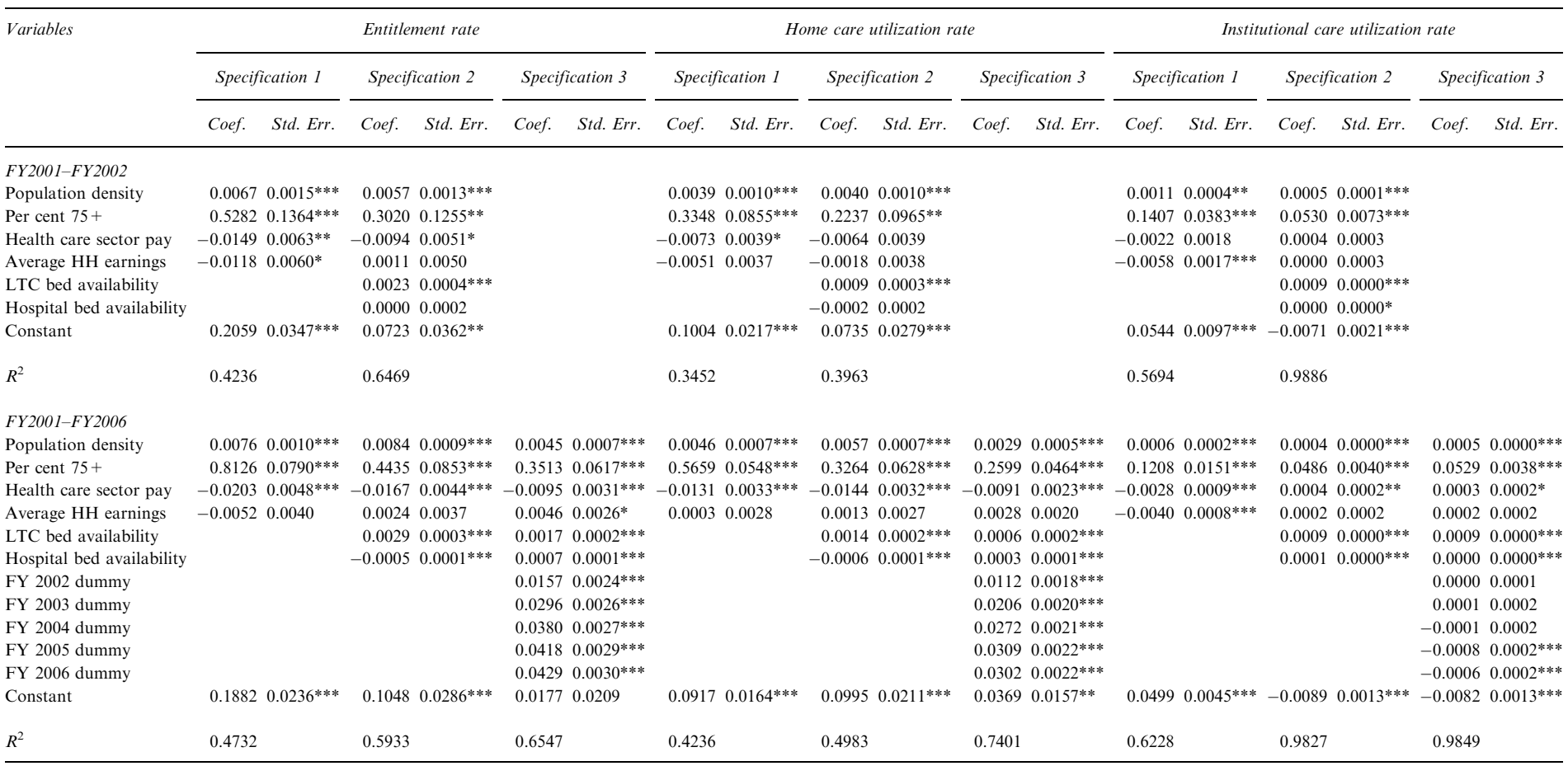

Source: Authors' computations. The estimation uses weighted least squared (WLS) method (where the weights depend on population size). Note: $* * *$ significant at 1 percent level; **significant at 5 per cent level; * significant at 10 per cent level. The number of observations is 94 ( 47 prefectures times 2 years) for the regressions in the upper panel and 282
$(47$ prefectures times 5 years) for the lower panel. The dependent variable is the share of those eligible for LTC (entitlement rate), home care users (home care utilization rate), and institutional care users (institutional care utilization rate) in the age $65+$ population in each prefecture. Independent variables include the population per kilometer-squared (population density), the share of age $75+$ in the population (per cent $75+$ ), annual pay including bonuses for staff and assistant nurses in 2005 levels (health care sector pay), annual household earnings in 2005 levels (Average HH Earnings), the number of LTC beds available, and the number of non-LTC hospital beds available. In the lower panels, year dummy variables are also included. 
income level is a proxy not only for wealth levels but also for user costs since higher income households must pay more for LTC. ${ }^{20}$ Specification 2 adds two capacity variables, namely the number of LTC and hospital beds per older $(65+)$ person, to assess whether utilization responds to capacity. If there is no response, this may be because beds are quantity-rationed. Specification 3 includes all the foregoing factors and also adds year controls to assess robustness of results. In order to address the fact that prefectures have different size populations, we employ weighted least squares regression.

Results are given in Table 3 where it can be seen that specification 1 is reasonable. Nevertheless we learn that, in some cases, the effects are much larger than found in prior analyses using the shorter time period. For instance, population density now is more positively and statistically significantly associated with overall entitlement rates and homecare utilization compared to our earlier study (the effect on institutional care is small and not substantially different). This suggests a widening discrepancy in LTC usage between urban and rural areas over the period. Similarly, the older the population (more people aged $75+$ ), the higher the LTC entitlement rates and utilization rates. Furthermore, the extended data set produces larger and more statistically robust coefficients particularly for entitlement and home-care utilization rates. This is not the case for institutional care use, for reasons we outline below. Moving on to the healthcare sector pay, the coefficients are negative and significant mainly for entitlement patterns and homecare use. This sensitivity of LTC patient usage, which holds after controlling for average household earnings, is probably a result of the co-insurance structure of the LTC insurance system, that is, higher income households must pay more for LTC. In contrast, average household earnings in the region are not statistically significant in most specifications.

Specification 2 includes as explanatory variables measures of bed availability for institutional and non-hospital care. It is interesting that bed availability for institutional care enters the entitlement and utilization rate equations positively. Nevertheless the coefficients are small, perhaps indicating excess demand from consumers, so that supply determines usage patterns. This is especially true for institutional care utilization, where availability accounts for most of the variation. Note that the coefficients on LTC bed availability are also positive and significant for entitlement rate or home-care utilization rate, suggesting some degree of supplier-induced demand for LTC. Specification 3 adds year dummies to specification 2; it is clear that entitlement and home-care usage are rising over time except home-care usage in FY 2006. This may be due to consumers learning about the new system over time.

Overall, we believe that our most important finding is the strong positive estimated coefficient on the proportion of the population $75+$. Evidently this group is obtaining higher levels of LTC services over time even after controlling for other factors. It is also worth noting that large regional disparities in age structure across the nation pose challenges for the "centralized" approach to LTC under the Japanese system. Local government reluctance to boost institutional care capacity is likely to instead direct increasing numbers of newly entitled elderly to home-care use. Whether this will ensure adequate treatment is unclear in the Japanese context; however, the U.S. 
literature on this topic indicates that home care is not a particularly effective substitute for nursing home care. ${ }^{21}$

\section{Discussion}

Most developed and ageing nations are looking with interest at how Japan is coping with a high and rising demand for LTC for its large and growing older population. The Japanese approach to the LTC model is a complex tax-and-transfer scheme, supported by mandatory but means-tested premiums levied on workers (pay-roll) by health insurers or retirees (pension benefits) by local governments, along with general tax revenue from central and local governments and out-of-pocket payments by beneficiaries. LTC eligibility is determined by local boards appointed by municipalities, but fees for benefits are set at the national level. As the Japanese system has been in place just a few years, there is as yet little information available with which to study the determinants of entitlement and utilization. Our goal has been to suggest what might be behind some of the recent utilization patterns using the most up-to-date information.

Two main findings on recent developments in Japanese LTC emerged using our time-series cross-section variations across prefectures. First, we find rapidly expanding use of LTC services, and second, we have identified widening regional disparity. Only a few years into the new programme, LTC entitlement rates in Japan have risen by as much as one-third, from 13 to 17 per cent for the age $65+$ population. Utilization rates are also up, mainly in the at-home care sphere, where usage has risen almost 50 per cent (vs. only 5 per cent for institutional care use). One of the important determinants of LTC use is the share of people aged $75+$, which is expected to increase in the future as Japan becomes a more aged society resulting in larger LTC use. Fukui and Iwamoto $^{22}$ project that the current system will imply a 63 per cent increase in future tax burdens to stay afloat; whether such an increase is feasible or whether it will require more fundamental reforms is a policy discussion that will soon require attention.

Our empirical results also suggest that future use of LTC in Japan will grow as the elderly consumers find subsidized at-home care preferable to, and more available than, conventional hospitalization. Noguchi and Shimizutani ${ }^{23}$ confirm that at-home care is becoming increasingly attractive to older persons, particularly when an older person has family members with whom he or she can live. This trend will be strengthened by local government reluctance to boost institutional care capacity, and it is likely to direct increasing numbers of newly entitled elderly to home-care use. In fact, the number of hospital beds per thousand persons aged $65+$ fell by 15 per cent on average, which was, as intended, offset by a 4 per cent increase in beds dedicated to LTC. In other words, it is clear that there has been a substantial change in the way care institutional capacity is being allocated to the elderly in Japan.

\footnotetext{
${ }^{21}$ Garber (1996).

${ }^{22}$ Fukui and Iwamoto (2006).

${ }^{23}$ Noguchi and Shimizutani (2002).
} 
At the same time, there remain sharp regional disparities in entitlement and utilization patterns which expanded in a short period, suggesting that the scheme in place that seeks to smooth these regional differences (using 5 per cent of total system revenue) has not resolved regional inequalities in treatment. In fact, local governments now confront tighter fiscal budgets into the future, so they are likely to have to clamp down on both entitlement and LTC care utilization in years to come. ${ }^{24}$ Large regional disparities in age-structure pose challenges for the "centralized" approach employed by the Japanese LTC programme.

To slow the LTC growth rate, several reforms have recently been announced by the government. ${ }^{25}$ Over the last year, for instance, the government has indicated that the elderly will be charged user fees for room and board costs at LTC institutions, whereas before the introduction of LTC insurance, these had been covered by the health insurance scheme. This new policy raises revenue, but it may also increase equity between institutionalized users vs. the at-home care patient population. Still, as Noguchi and Shimizutani ${ }^{26}$ have noted, the price elasticity for institutional care is negligible so the short-term impact of increasing costs for institutional care will not likely influence utilization by much. And Yamada et al. ${ }^{27}$ examined behavioural choice between the nursing home care and community-based formal/informal home care among the elderly and showed that developing community-based formal/informal home care would lead to economic gains.

The government has also recently announced the introduction of "preventive services" for those elderly predicted to be at risk of needing care in future, hoping with this policy to reduce the need for future LTC usage with an early intervention programme. This drive is paired with local government health examinations on persons aged $65+$ to screen those who might benefit from home support services. These services include exercise and nutritional guidance as well as home-visit services, day services, and other preventive measures. While this effort may prove useful, so far only 0.2 per cent has received such care, even though the Ministry of Health, Welfare and labour estimated that the group at risk would comprise 5 per cent of the elderly. A further, and fairly dramatic, reform that will be gradually implemented by 2012 is that all hospital beds for LTC will be phased out. This is a decisive phase of the drive to reduce "social hospitalization" and reduce medical care cost escalation.

It is too early to measure the full effect of these recent reforms, but there is speculation that those policies may have only a small impact on future growth rates of LTC usage. Other policies debated but yet not instituted include merging the LTC insurance system with the national disability support programme, and lowering the age of the workforce paying for the LTC system from 40 to 20 to finance future deficits in the LTC programme. Compliance may well be an issue in implementation, however. Our results suggest that when fiscal cost becomes an issue driving reform, it might be sensible to give priority to policies that enhance the efficiency of existing LTC programmes.

\footnotetext{
${ }^{24}$ Shimizutani and Inakura (2007).

${ }^{25}$ JMHLW (no date).

${ }^{26}$ Noguchi and Shimizutani (2002).

27 Yamada et al. (2006).
} 
Additional reforms could include mechanisms to strengthen the market for privately provided LTC insurance, insofar as older persons can muster sufficient income/assets to buy the coverage.

Given the steady demographic shift in Japan, responsibility for providing care to the frail elderly is sure to grow ever more expensive. The public insurance scheme will face tightening fiscal and capacity constraints, suggesting that there may be room for a private LTC market in a complementary role to the public programme. It may also be possible for reverse mortgages to be used in Japan as a means of financing services and providing care for the nation's growing elderly population. ${ }^{28}$ In these ways, it will be possible to expand the range of products available for retirement security beyond the public insurance programme.

\section{References}

Campbell, J. and Ikegami, C. (1998) The Art of Balance in Health Policy: Maintaining Japan's Low-Cost Egalitarian System, Cambridge: Cambridge University Press.

Campbell, J.C. and Ikegami, N. (2000) 'Long-term care insurance comes to Japan', Health Affairs 19(3): 26-39.

Fukui, T. and Iwamoto, Y. (2006) Policy options for financing the future health and long-term care costs in Japan, NBER Working Paper 12427, Washington, DC.

Garber, A. (1996) 'To comfort always: The prospects of expanded social responsibility for long-term care', in V. Fuchs (ed) Individual and Social Responsibility, Chicago: NBER and University of Chicago Press, pp. 143-174.

Ikegami, N. (2003) Japan's health care system: Containing costs in a stagnant economy, Presentation for The Wharton School, October.

Ikegami, N. and Campbell, J. (1999) 'Health care reform in Japan: The virtues of muddling through', Health Affairs 18(May/June): 56-75.

Ikegami, N. and Yamada, T. (1996) 'Comparison of long-term care for the elderly between Japan and the United States', in N. Ikegami and J. Campbell (eds) Containing Health Care Costs in Japan, Ann Arbor: University of Michigan Press, pp. 155-171.

Japan Ministry of Health, Labour and Welfare (JMHLW) (2002) 'Long-term Care Insurance in Japan', Tokyo, from http://www.mhlw.go.jp/english/topics/elderly/care/index.html.

Japan Ministry of Health, Labour and Welfare (JMHLW) (2003) 'Elderly Care in 2015: Establishing Elderly Care to Support Dignity of the Elderly' (in Japanese), Tokyo, from http://www.mhlw.go.jp/topics/kaigo/ kentou/15kourei/index.html.

Japan Ministry of Health, Labour and Welfare (JMHLW) (no date) Kaigo hoken seido kaikaku no gaiyou (An overview of the LTC insurance reform), Tokyo.

Mitchell, O.S. and Piggott, J. (2004) 'Unlocking housing equity in Japan', Journal of the Japanese and International Economies 18: 466-505.

Mitchell, O.S., Piggott, J. and Shimizutani, S. (2006) 'Aged-care support in Japan: Perspectives and challenges', Benefits Quarterly 22: 7-18.

Noguchi, H. and Shimizutani, S. (2002) The determinants of nursing home exit and the price elasticity of institutional care: Evidence from Japanese micro-level data, ESRI Discussion Paper 24, Tokyo, December.

Ogawa, N., Mason, A., Maliki, R. and Nemoto, K. (2007) 'Population aging and health care spending in Japan: Public- and private-sector responses', in R. Clark, A. Mason and O. Naohiro (eds) Population Aging, Intergenerational Transfers and the Macroeconomy, London: Edward Elgar, pp. 192-226.

Shimizutani, S. and Inakura, T. (2007) 'Japan's public long-term care insurance and the financial condition of insurers: Evidence from municipality-level data', Government Auditing Review 14: 27-40.

${ }^{28}$ Mitchell and Piggott (2004). 
Yamada, T., Chen, C., Yamada, T., Fahs, M. and Fukawa, T. (2006) 'Behavioral analysis of the choice of community-based formal home care, informal home care and nursing home care in Japan', The Geneva Papers on Risk and Insurance - Issues and Practice 31: 600-632.

Yashiro, N., Oshio, T., Terasaki, Y. and Miyamoto, M. (1996) An economic analysis on long-term care insurance, Working Paper, Institute of Economics, Economic Planning Agency, Tokyo.

Yashiro, N., Suzuki, R. and Suzuki, W. (2006) 'Evaluating Japan's health care reform of the 1990s and its efforts to cope with population aging', in D. Wise and N. Yashiro (eds) Health Care Issues in the US and Japan, Chicago: University of Chicago Press, pp. 17-111.

\section{About the Authors}

Olivia S. Mitchell is the International Foundation of Employee Benefit Plans Professor of Insurance and Risk Management; Executive Director of the Pension Research Council; and Director of the Boettner Center on Pensions and Retirement Research at the Wharton School of the University of Pennsylvania. She received her B.A. in Economics from Harvard University and her M.A. and Ph.D. in Economics from the University of Wisconsin-Madison. She served on President Bush's Commission to Strengthen Social Security.

John Piggott is Associate Dean Research at the Australian School of Business and Professor of Economics at the University of New South Wales in Sydney, Australia, where he also directs the Australian Institute of Population Ageing Research. His B.A. is from the University of Sydney and his M.Sc. and Ph.D. degrees from the University of London. Previous appointments include positions at the University of Western Ontario in Canada and the Australian National University, Canberra.

Satoshi Shimizutani is a Senior Research Fellow at Japan's Institute for International Policy Studies. He received a Bachelor of Laws from the University of Tokyo and a Ph.D. in Economics from the University of Michigan. He has worked for the Japanese Economic Planning Agency (Cabinet Office, Government of Japan) in several different offices as staff economist and deputy director. He has also served on the Faculty of the Institute for Economic Research of Hitotsubashi University. 


\section{Data Appendix}

\begin{tabular}{|c|c|c|c|c|c|}
\hline Variables & & Description & Unit & Definition & Source and Note \\
\hline \multicolumn{2}{|l|}{ Entitlement rate } & $\begin{array}{l}\text { Number of people entitled out of } \\
\text { population age } 65+\end{array}$ & $\%$ & $\begin{array}{l}\text { entl_tot/ } \\
(\text { eld } 65 \times 1,000)\end{array}$ & $\begin{array}{l}\text { All-Japan Federation of National Health Insurance } \\
\text { Organization: http://www.kokuho.or.jp } \\
\text { Note: Monthly data. } \\
\text { Data in October in } 2001-2006 \text { was used. }\end{array}$ \\
\hline \multicolumn{2}{|l|}{$\begin{array}{l}\text { Home care utilization } \\
\text { rate }\end{array}$} & $\begin{array}{l}\text { Number of at-home care users in } \\
\text { population aged } 65+\end{array}$ & $\%$ & $\begin{array}{l}\text { uhm_tot/ } \\
(\text { eld } 65 \times 1,000)\end{array}$ & Ibid. \\
\hline \multirow[t]{7}{*}{$\begin{array}{l}\text { Institutional care } \\
\text { utilization rate }\end{array}$} & & $\begin{array}{l}\text { Number of institutional care users in } \\
\text { population aged } 65+\end{array}$ & $\%$ & $\begin{array}{l}\text { uinst_tot/ } \\
(\text { eld } 65 \times 1,000)\end{array}$ & Ibid. \\
\hline & entl_tot & Number of people entitled for LTC & Person & & Ibid. \\
\hline & uhm_tot & $\begin{array}{l}\text { Number of people using at-home care } \\
\text { services }\end{array}$ & Person & & Ibid. \\
\hline & uinst_tot & $\begin{array}{l}\text { Number of people using institutional } \\
\text { care }\end{array}$ & Person & & Ibid. \\
\hline & eld65 & Population $65+$ & Thousand & & $\begin{array}{l}\text { Japan Statistics Bureau: http://www.stat.go.jp/data/jinsui/ } \\
\text { 2.htm } \# 01\end{array}$ \\
\hline & & & & & $\begin{array}{l}\text { Note: Annual data. Population projection for } 2001-2004 \text { and } \\
2006\end{array}$ \\
\hline & & & & & Census for 2005 \\
\hline \multirow[t]{5}{*}{ Population density } & & Number of people per square kilometer & $\begin{array}{l}1,000 \\
\text { person } / \mathrm{km}^{2}\end{array}$ & pop_tot/area2 & \\
\hline & pop_tot & Total population & Thousand & & $\begin{array}{l}\text { Japan Statistics Bureau: http://www.stat.go.jp/data/jinsui/ } \\
\text { 2.htm } \# 01\end{array}$ \\
\hline & & & & & Note: Annual data. \\
\hline & & & & & $\begin{array}{l}\text { Population projection for } 2001-2004 \text { and } 2006 \\
\text { Census for } 2005\end{array}$ \\
\hline & area2 & Area of prefectures & $\mathrm{Km}^{2}$ & & $\begin{array}{l}\text { Geographical Survey Institute: http://www.gsi.go.jp/ } \\
\text { KOKUJYOHO/MENCHO/200510/ichiran.htm }\end{array}$ \\
\hline
\end{tabular}




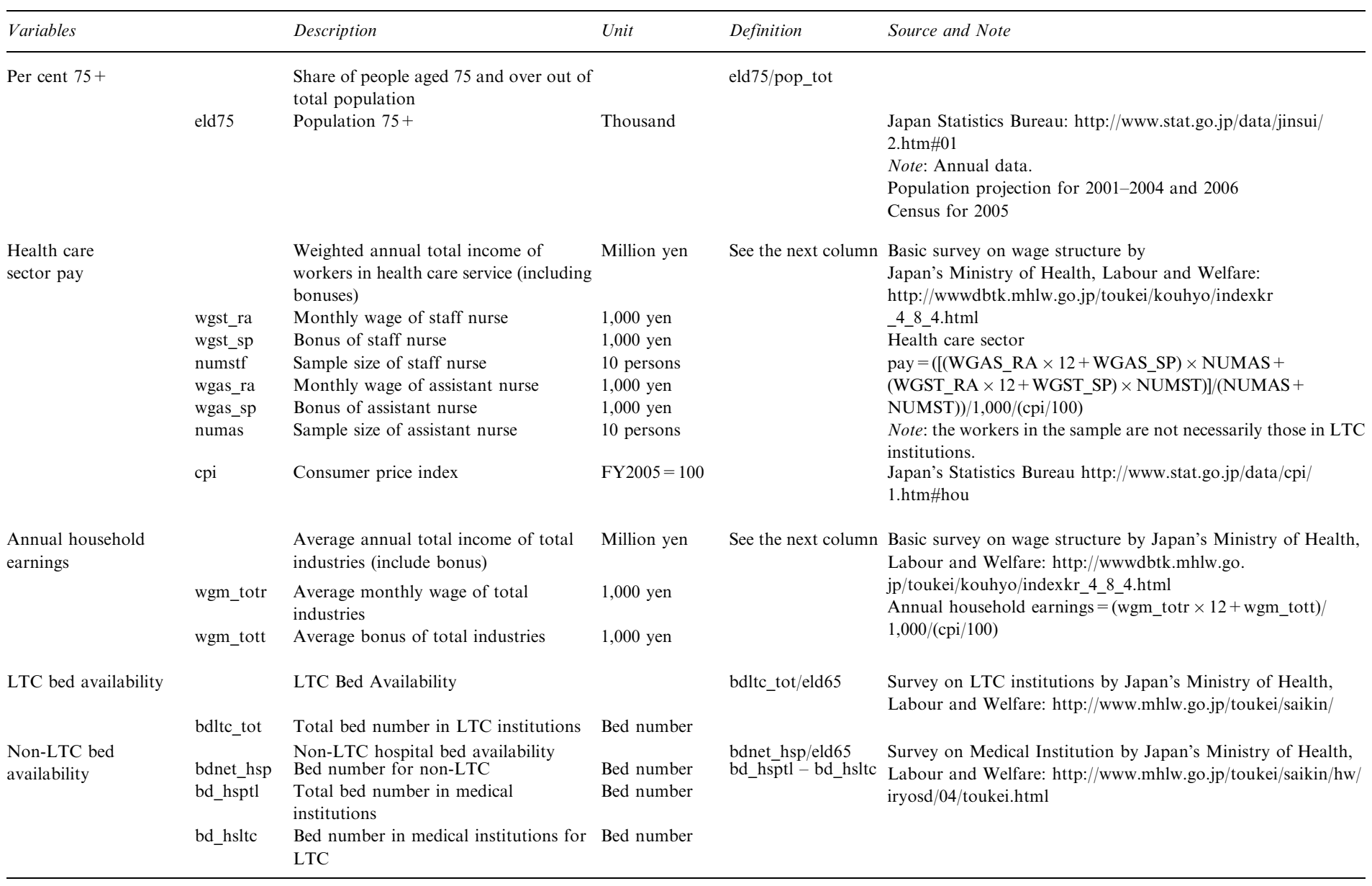

